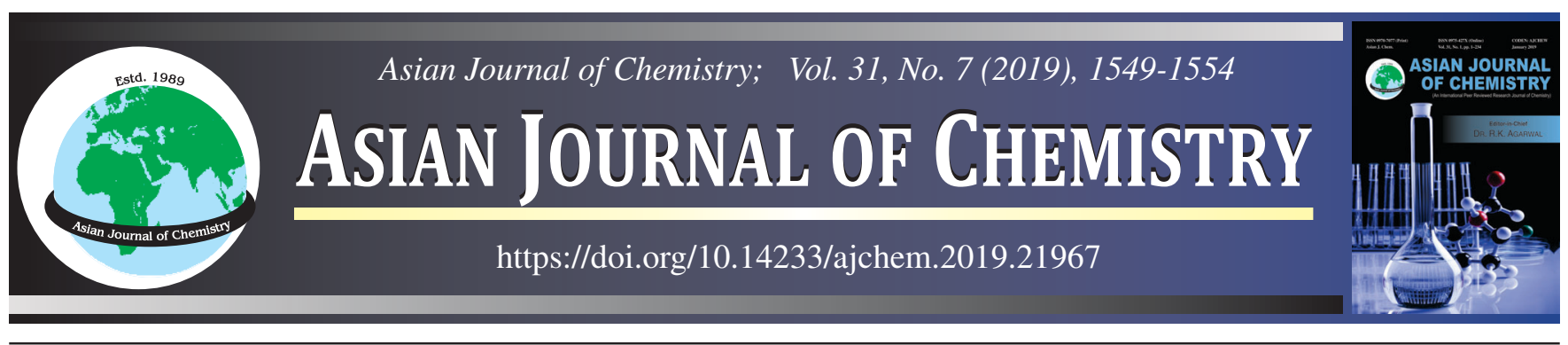

\title{
Exploration on Anticorrosive, Antibacterial and Osteocompatibility Properties of Samarium/Europium Substituted Hydroxyapatite Coating on Surgical Grade Stainless Steel for Biomedical Applications
}

\section{SRIDEvi ${ }^{1}$, S. Sathishikumar ${ }^{2}$, P. KarthikeYan ${ }^{3}$ and P. MaheSWARAN ${ }^{1, *}$}

${ }^{1}$ Department of Chemistry, P.G.P. College of Arts and Science, Namakkal-637207, India

${ }^{2}$ Department of Chemistry, Sri Vijay Vidyalaya College of Arts and Science, Dharmapuri-636807, India

${ }^{3}$ Department of Chemistry, Periyar University Constituent College of Arts and Science, Idappadi-637102, India

*Corresponding author: E-mail: drmahes2017pgp@gmail.com

Received: 28 January 2019;

Accepted: 24 March 2019;

Published online: 21 May 2019;

AJC-19412

In present work, samarium/europium substituted hydroxyapatite (Sm/Eu-HAP) coating on 316L stainless steel has been carried out by
electrodeposition method. The surface characteristics of the developed coating were assessed by Fourier transform infrared spectroscopy
(FT-IR), X-ray diffraction (XRD), High resolution scanning electron microscopy (HRSEM) and energy dispersive X-ray analysis. The
special effects of Sm/Eu-HAP coating on anticorrosion behaviour of $316 \mathrm{~L}$ stainless steel were also studied using electrochemical analysis
in the Ringers solution. The antibacterial activity and in vitro live/dead assay of Sm/Eu-HAP coating were investigated. As a result of
these examinations, revealed that $\mathrm{Sm} /$ Eu-HAP coating on $316 \mathrm{~L}$ stainless steel enhanced the corrosion resistance performance and
significantly improved the bioactivity. Thus, Sm/Eu-HAP coating can play an important role in biomedical applications.
Keywords: Substituted hydroxyapatite, Electrodeposition, Corrosion resistance, Antibacterial activity, Osteocompatibility.

ᄂ _ - - - - - - - - - - - - - - - - - - - - - - - - - - - - - -

\section{INTRODUCTION}

Biomedical implants have received much interest and intensive research during last few decades as they are used as replacement material of various body parts or organs. For this a purpose, metallic material which combines good mechanical characteristics, high corrosion resistance and good compatibility with any of the biological materials, need to be chosen. The austenitic stainless steel in particular 316L stainless steel profits of low cost, high corrosion resistance, excellent biocompatibility and ease of fabrication. It is due to creation of passive chromium oxide layer on the surface. This protecting oxide layer release of chromium, iron and nickel ions evidenced in the human body [1-7]. Hence the surface treatment for the specimens is imperative to improvement of corrosion resistance on 316L stainless steel in physiogical environment. In order to ensure their long term clinical application and to enhance the bioactivity of $316 \mathrm{~L}$ stainless steel implants a bio ceramic material with osteoconductive property is often coated on the metallic implants [7-10]. Among the materials used for coating, hydroxyapatite $\left[\mathrm{HAP}, \mathrm{Ca}_{10}\left(\mathrm{PO}_{4}\right)_{6}(\mathrm{OH})_{2}\right]$ is the best biocompatible and bioactive material that acts as a bridge between implant and human tissue thereby improving the osseointegration $[11,12]$. Hydroxyapatite in bone is a multi-substituted calcium phosphate, including traces of $\mathrm{Mg}^{2+}, \mathrm{Sr}^{2+}, \mathrm{Si}^{4+}, \mathrm{CO}^{2-}, \mathrm{Ba}^{2+}, \mathrm{Zn}^{2+}$ and $\mathrm{F}^{-}$, etc. [13-15]. Hence, the ionic substituted HAP plays an important role in bone formation. There are also several studies on the synthesis and coating of the metal ion substituted HAP which has been shown to improve its structural stability and cellular biocompatible properties. But the rare earth ions (Sm, La, Gd, Eu, etc.) substituted HAP has been rarely reported. The lanthanide ions have related ionic radius in $\mathrm{Ca}^{2+}$, so the great attraction in bone linked biological molecules. Several important features of lanthanide ions professed in biological properties. Hence, Sm-HAP has been used in the subject of great interest due to the significant role of this ion in the improved osteoblastic performance, good antibacterial properties and biologically bone targeted radio therapeutic agent play in preventing caries $[16,17]$. The samarium ions have been used for bone metastatic prostate cancer and depen-

This is an open access journal, and articles are distributed under the terms of the Creative Commons Attribution-NonCommercial-ShareAlike 4.0 (CC BY-NC-SA 4.0) International License which allows readers to freely read, download, copy, distribute, print, search, or link to the full texts of its articles and to use them for any other lawful non-commercial purpose as long as the original source is duly acknowledged. 
dent on prior treatments. Hence the presence of a samarium ions improved the potential of corrosion and pitting of the inhibitor of steels and aluminum in neutral medium due to use in industrial application. In addition different studies have used in Sm-153 hydroxyapatite as good physical and radiobiological properties due to treatment of chronic and knee synovitis [18]. On other hand, to developed secondary material with good bioactivity can be introduced. For this purpose, the europium ion, a functional mimics of the calcium ions that can affect the bone remodeling cycle and are potentially used for the treatment of bone density disorders such as osteoporosis, is introduced into HAP along with samarium [19]. This is the first effort by the authors to improve a coating of $\mathrm{Sm} / \mathrm{Eu}$ substituted hydroxyapatite on stainless steel by electrodeposition technique and to our best of knowledge there are no other reports so far.

\section{EXPERIMENTAL}

316L Stainless steel specimen preparation: Type 316L stainless steel (procured from Steel Authority of India, Ltd., India), having an elemental composition (wt \%) of $0.0222 \mathrm{C}$, $0.551 \mathrm{Si}, 1.67 \mathrm{Mn}, 0.023 \mathrm{P}, 0.0045 \mathrm{~S}, 17.05 \mathrm{Cr}, 11.65 \mathrm{Ni}, 2.53$ $\mathrm{Mo}, 0.136 \mathrm{Co}, 0.231 \mathrm{Cu}, 0.0052 \mathrm{Ti}, 0.0783 \mathrm{~V}, 0.0659 \mathrm{~N}$ and $\mathrm{Fe}$ (balance), was used as the metal substrate for the ED. The $316 \mathrm{~L}$ stainless steel substrate with a size of $10 \mathrm{~mm} \times 10 \mathrm{~mm} \times$ $3 \mathrm{~mm}$ were embedded in epoxy resin, leaving an area of $1 \mathrm{~cm}^{2}$ for exposure to the electrolyte solution. Before to ED, these specimens were abraded with different grades of silicon carbide papers from 400 to 1200 grit. After polishing, these specimens were ultrasonically cleaned and exhaustively washed with acetone and deionized water for $10 \mathrm{~min}$ and finally, rinsed in deionized water and dried.

Surface passivation of $316 \mathrm{~L}$ stainless steel specimens: In order to enhance the bio resistivity of the $316 \mathrm{~L}$ stainless steel surface was passivated using $0.4 \mathrm{M}$ borate buffer solution $(\mathrm{pH} \mathrm{9.3)}$ at $640 \mathrm{mV} v s$. saturated calomel electrode (SCE) for $2 \mathrm{~h}$ in potentiostatic condition using electrochemical workstation (Model CHI 760C, CH Instruments, USA).

Preparation of electrolyte solution: The electrolyte solution for prepared by dissolving analytical grade $0.3 \mathrm{M}$ calcium nitrate hexahydrate, $0.1 \mathrm{M}$ samarium nitrate hexahydrate and $0.1 \mathrm{M}$ europium nitrate hexahydrate in deionized water. The $0.3 \mathrm{M}$ diammonium hydrogen phosphate solution was dissolved in deionized water and the solution was mixed with $(\mathrm{Ca}+$ $\mathrm{Sm}+\mathrm{Eu}) / \mathrm{P}$ molar ratio of 1.67 at room temperature $(28 \pm 1$ $\left.{ }^{\circ} \mathrm{C}\right)$. Then the solution was under magnetic stirring for $4 \mathrm{~h}$ and the $\mathrm{pH}$ of the electrolyte was adjusted to 4.7 using ammonia hydroxide solution. All the chemicals were analytic grade reagents (purchased from sigma Aldrich) and used without further purification.

Development of Sm/Eu-HAP coating: Sm/Eu-HAP coating route on $316 \mathrm{~L}$ stainless steel was carried out in galvanostatically for $60 \mathrm{~min}$ at various current densities of 8,9 and $10 \mathrm{~mA} / \mathrm{cm}^{2}$. After the electrodeposition Sm/Eu-HAP coating substrates were gently rinsed with deionized water dried in the air and then stored in a desiccator for further investigations.

Surface characterization of $\mathrm{Sm} / \mathrm{Eu}$-HAP coating: The identification of functional groups in Sm/Eu-HAP coating materials were analyzed by Fourier transform infrared (FTIR) spectroscopy. The phase composition of coated samples was studied by X-ray diffraction PANalytical X'Pert PRO diffractometer in the $2 \theta$ angle between $20^{\circ}-60^{\circ}$ with $\mathrm{Cu} \mathrm{K}_{\alpha}$ radiation (1.5406 $\AA$ ). The surface morphology and elemental composition of as a developed $\mathrm{Sm} / \mathrm{Eu}-\mathrm{HAP}$ coating were evaluated by a high resolution scanning electron microscopy (HRSEM, JSM 840A, JEOL-Japan) equipped with EDAX.

Antibacterial activity: The in vitro antibacterial activity of Sm/Eu-HAP coating at different concentrations have been investigated against two prokaryotic strains such as $S$. aureus (ATCC 25923) and E. coli (ATCC 25922) through agar disc diffusion method. The Mullar-Hinton agar plates were prepared by pouring $15 \mathrm{~mL}$ of a molten medium into sterile Petri plates. The plates were allowed to solidify for $\sim 15 \mathrm{~min}$ and $0.1 \%$ of inoculum suspension was swabbed uniformly over the agar until the inoculums became invisible. Different concentrations $(25,50,75,100$ and $125 \mu \mathrm{L})$ of $\mathrm{Sm} / \mathrm{Eu}-\mathrm{HAP}$ coating were loaded onto $5 \mathrm{~mm}$ sterile individual discs, followed by incubation of plates at $37{ }^{\circ} \mathrm{C}$ for $24 \mathrm{~h}$. The zone of inhibition was observed by measuring the width of the inhibited zone.

Osteocompatibility analysis: The cell proliferation of MC3T3-E1 cells on Sm/Eu-HAP was studied using MTT assay on day 1,3 and 5. To determine the cytotoxicity of the samples at different conditions, MC3T3-E1 cells were seeded in 12-well plates at 104 cells $/ \mathrm{mL}$ in a humidified $5 \% \mathrm{CO}_{2}$ atmosphere. Each time, $400 \mu \mathrm{L}$ of MTT reagent $(1 \mathrm{mg} / \mathrm{mL})$ was added to each well and incubated for $4 \mathrm{~h}$ under the same conditions. Finally, MTT reagent was removed and $400 \mu \mathrm{L}$ of dimethyl sulfoxide was added for dissolving the form as an crystals and the absorbance was measured at $560 \mathrm{~nm}$ in an ELISA microplate reader and then the cell viability (as a percentage) was calculated, with respect to the control, as follows:

$$
\text { Cell viability }(\%)=\frac{[\mathrm{A}] \text { Test }}{[\mathrm{A}] \text { Control }} \times 100
$$

\section{RESULTS AND DISCUSSION}

FT-IR analysis: The FT-IR spectra of Sm/Eu-HAP coating on 316L stainless steel are given in Fig. 1. The characteristic bands detected at 1092.39, 1040.44, 961.63, 603.13, 569.38 and $472.51 \mathrm{~cm}^{-1}$ correspond to the $\mathrm{PO}_{3}{ }^{4}$ group. Additionally, the characteristic $-\mathrm{OH}$ bands of HAP at around 3571.24 and $633.91 \mathrm{~cm}^{-1}$ correspond to the stretching and bending modes. The bands at 3427.87 and $1642.93 \mathrm{~cm}^{-1}$ were assigned to the stretching and bending mode of the adsorbed water molecule. As a result, the spectrum strongly demonstrated the formation of Sm/Eu-HAP coating on 316L stainless steel and no other impurities were identified.

$\mathrm{X}$-ray diffraction studies: Fig. 2 shows the X-ray diffraction patterns of Sm/Eu-HAP coating on 316L stainless steel respectively. The main diffraction peaks observed for $\mathrm{Sm} / \mathrm{Eu}-$ HAP are in well agreement with the standard data for HAP (ICDD card No. 09-0432). In this regard, the main diffraction peaks (Fig. 2) are showed at $2 \theta$ values of $25.8^{\circ}(002), 31.5^{\circ}$ (211), $32.2^{\circ}(112), 32.8^{\circ}(300) 34.6^{\circ}(202), 39.8^{\circ}(310), 46.6^{\circ}$ (222), $49.26^{\circ}$ (213) and 53.1(004) corresponds to Sm/Eu-HAP and no other secondary peaks were found. In consequence, 


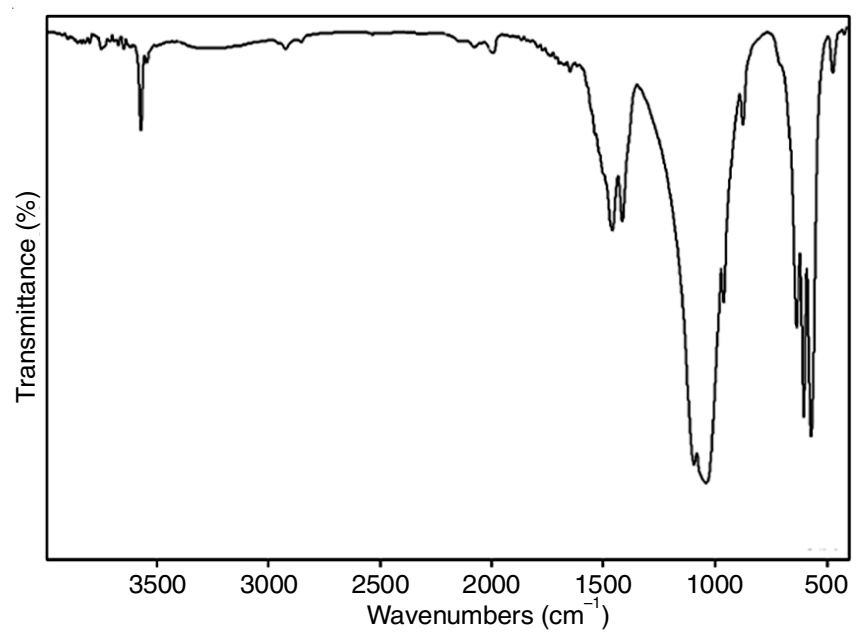

Fig. 1. FT-IR spectra of Sm/Eu-HAP coating

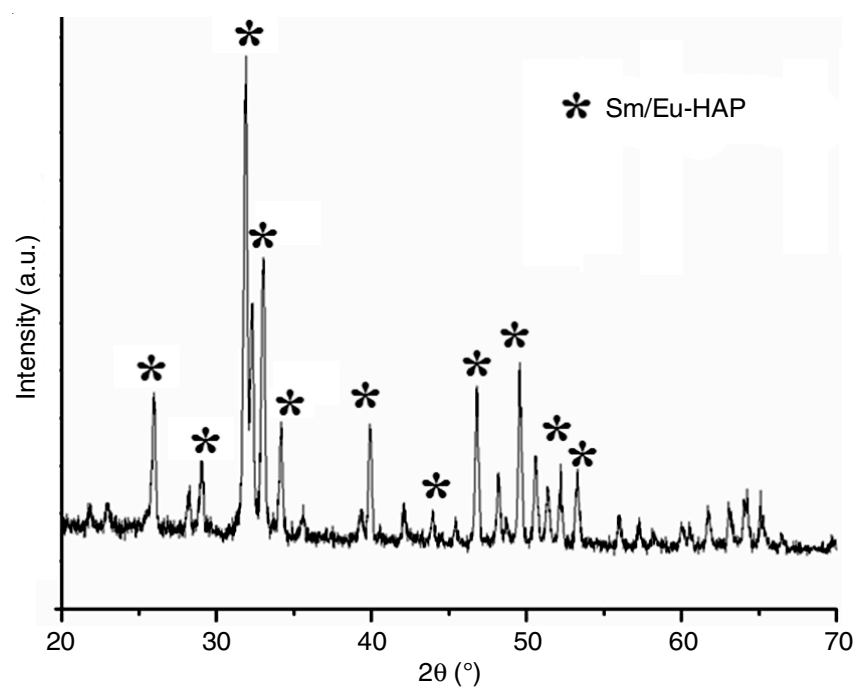

Fig. 2. XRD pattern of Sm/Eu-HAP coating

$\mathrm{Sm} / \mathrm{Eu}$-HAP coating demonstrated that the as-developed coating are in high crystalline in nature and purity.

Scanning electron microscopic and elemental analysis: The HRSEM morphology of Sm/Eu-HAP coating on 316L stainless steel by electrodeposition at 8,9 and $10 \mathrm{~mA} / \mathrm{cm}^{2}$ for 60 min are displayed in Fig. 3(a-c) and the elemental composition of $\mathrm{Sm} / \mathrm{Eu}-\mathrm{HAP}$ coating an optimum $9 \mathrm{~mA} / \mathrm{cm}^{2}$ is represented in Fig. 3(d). Fig. 3(a) and (c) indicates the morphology of Sm/Eu-HAP coating ( 8 and $10 \mathrm{~mA} / \mathrm{cm}^{2}$ ) consisted of rod like structure. The structure was not uniform and contained some agglomeration as shown in Fig. 3(a) and (c). The surface morphology of Sm/Eu-HAP $\left(9 \mathrm{~mA} / \mathrm{cm}^{2}\right)$ coated on $316 \mathrm{~L}$ stainless steel [Fig. 3(b)] exhibited the formation of completely covered the rod like structure and hence it is considered as optimum. Fig. 3(d) represents the EDAX spectrum of the $\mathrm{Sm} / \mathrm{Eu}-\mathrm{HAP}$ coating on $316 \mathrm{~L}$ stainless steel, which also founds the presence of Sm, Eu, Ca, P and O on Sm/Eu-HAP coated surface. This results supports for the creation of Sm/Eu-HAP coating on 316L stainless steel.

\section{Electrochemical studies}

Potentiodynamic polarization studies: Representative potentiodynamic polarization curves of uncoated, HAP coated, $\mathrm{Sm} / \mathrm{Eu}-\mathrm{HAP}$ coated on $316 \mathrm{~L}$ stainless steel in Ringer solution are shown in Fig. 4. As demonstrated from electrochemical values of the polarization parameters such as corrosion potential $\left(\mathrm{E}_{\text {corr }}\right)$,breakdown potential $\left(\mathrm{E}_{\mathrm{b}}\right)$ and repassivation potential $\left(\mathrm{E}_{\mathrm{pp}}\right)$ for the uncoated $316 \mathrm{~L}$ stainless steel were found to be at $-865,+447$ and $-88 \mathrm{mV} v s$. SCE, respectively. While the HAP coated samples showed $\mathrm{E}_{\mathrm{corr}}, \mathrm{E}_{\mathrm{b}}, \mathrm{E}_{\mathrm{pp}}$ values of $-790,+502$ and $185 \mathrm{mV} v \mathrm{~s}$. SCE, respectively. For the polarization parameters of Sm/Eu-HAP coated 316L stainless steel samples revealed $\mathrm{E}_{\text {corr }}, \mathrm{E}_{\mathrm{b}}, \mathrm{E}_{\mathrm{pp}}$ values of $-621,+709$ and $297 \mathrm{mV} v \mathrm{~s}$. SCE, respectively. These $\mathrm{E}_{\text {corr }}, \mathrm{E}_{\mathrm{b}}, \mathrm{E}_{\mathrm{pp}}$ values of Sm/Eu-HAP coated $316 \mathrm{~L}$ stainless steel sample indicated a maximum shift in the noble direction when compared to that of HAP coated and the uncoated 316L stainless steel specimens. In particular positive shift of $\mathrm{Sm} / \mathrm{Eu}-\mathrm{HAP}$ coated 316L stainless steel specimen possessed maximum anticorrosion behaviour in Ringers solution.

Electrochemical impedance spectroscopy studies (EIS): Electrochemical impedance spectroscopy studies is the most significant method, which can offer the valuable information on anticorrosion performance of all the coated 316L stainless steel specimens in the Ringers solution. The nyquist plots obtained for the uncoated, HAP coated and Sm, Eu-HAP coated 316L stainless steel specimens in ringers solution are shown in Fig. 4(b). The polarization resistance $\left(R_{p}\right)$ of Sm/Eu-HAP coating on $316 \mathrm{~L}$ stainless steel which exhibit polarization resistance $\left(R_{p}\right) 1806 \Omega \mathrm{cm}^{2}$ which is greater than that of HAP coated on $316 \mathrm{~L}$ stainless steel $\left(\mathrm{R}_{\mathrm{p}}\right) 796 \Omega \mathrm{cm}^{2}$ and uncoated 316L stainless steel $\left(R_{p}\right) 45 \Omega \mathrm{cm}^{2}$. From the Electrochemical impedance spectroscopy results Sm/Eu-HAP coated 316L stainless steel is more corrosion protective than the HAP coated and uncoated $316 \mathrm{~L}$ stainless steel specimens.

Antibacterial activity: The antibacterial ability of Sm/ Eu-HAP coating at five various concentrations was tested against the two prokaryotic strains E. coli and S. aureus are Gram-negative bacteria and Gram-positive bacteria by the disc diffusion method. The zone of inhibition around the $\mathrm{Sm} / \mathrm{Eu}-$ HAP coated samples at different concentrations $(25,50,75$, 100 and $125 \mathrm{~mL}$ ) against E. coli and S. aureus is showed in Fig. 5. The antibacterial activity results indicated the $\mathrm{Sm} / \mathrm{Eu}-$ HAP coating samples displayed superb antibacterial activity against the two bacterial strains. The reason may be owed the incorporation of $\mathrm{Sm}$ ions plays an important role in enhancing the antibacterial activity. In specific the activity of Sm/EuHAP against $E$. coli bacteria slightly higher when compared to the $S$. aureus bacteria.

in vitro cytotoxicity and live/dead analysis: The cell viability of MC3T3-E1 cells on Sm/Eu-HAP coated samples were evaluated using MTT assay and the results showed in Fig. 6. The absorbance of cell viability at $570 \mathrm{~nm}$ is directly proportional to the number of living cells in MC3T3-E1 cell culture medium. The $\%$ cell viability on $100 \mu \mathrm{g} / \mathrm{mL}$ of coatings at 1, 3, 5 and 7 days of culture is indicated in Fig. 6. It is evidently that $\mathrm{Sm} / \mathrm{Eu}$-HAP coating exhibited the number of viable cells growth and without any toxic effect. The cell viability results should be significant and improvement of biological performance.

The live/dead fluorescence microscopic results of Sm/EuHAP coated samples cultured at 1, 3, 5 and 7 days displayed in Fig. 7. The live/dead images indicating the green cell are 

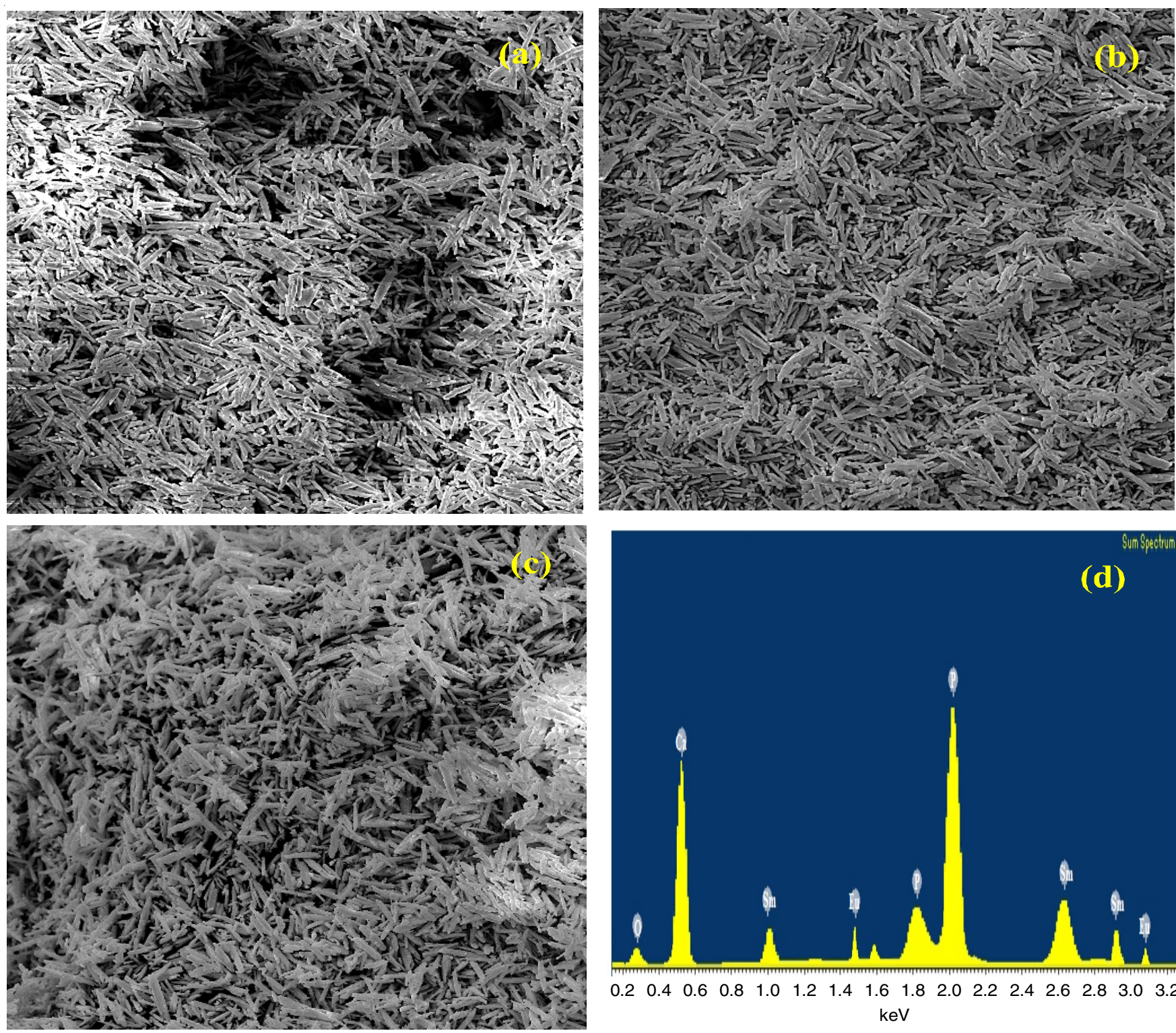

$\begin{array}{lllllllllllllllll}0.2 & 0.4 & 0.6 & 0.8 & 1.0 & 1.2 & 1.4 & 1.6 & 1.8 & 2.0 & 2.2 & 2.4 & 2.6 & 2.8 & 3.0 & 3.2\end{array}$ $\mathrm{keV}$

Fig. 3. SEM micrographs of (a) Sm/Eu-HAP coating on $8 \mathrm{~mA} / \mathrm{cm}^{2}$ (b) Sm/Eu-HAP coating on $9 \mathrm{~mA} / \mathrm{cm}^{2}$ (c) Sm/Eu-HAP coating on $10 \mathrm{~mA} /$ $\mathrm{cm}^{2}$ (d) EDAX spectrum of Sm/Eu-HAP coating
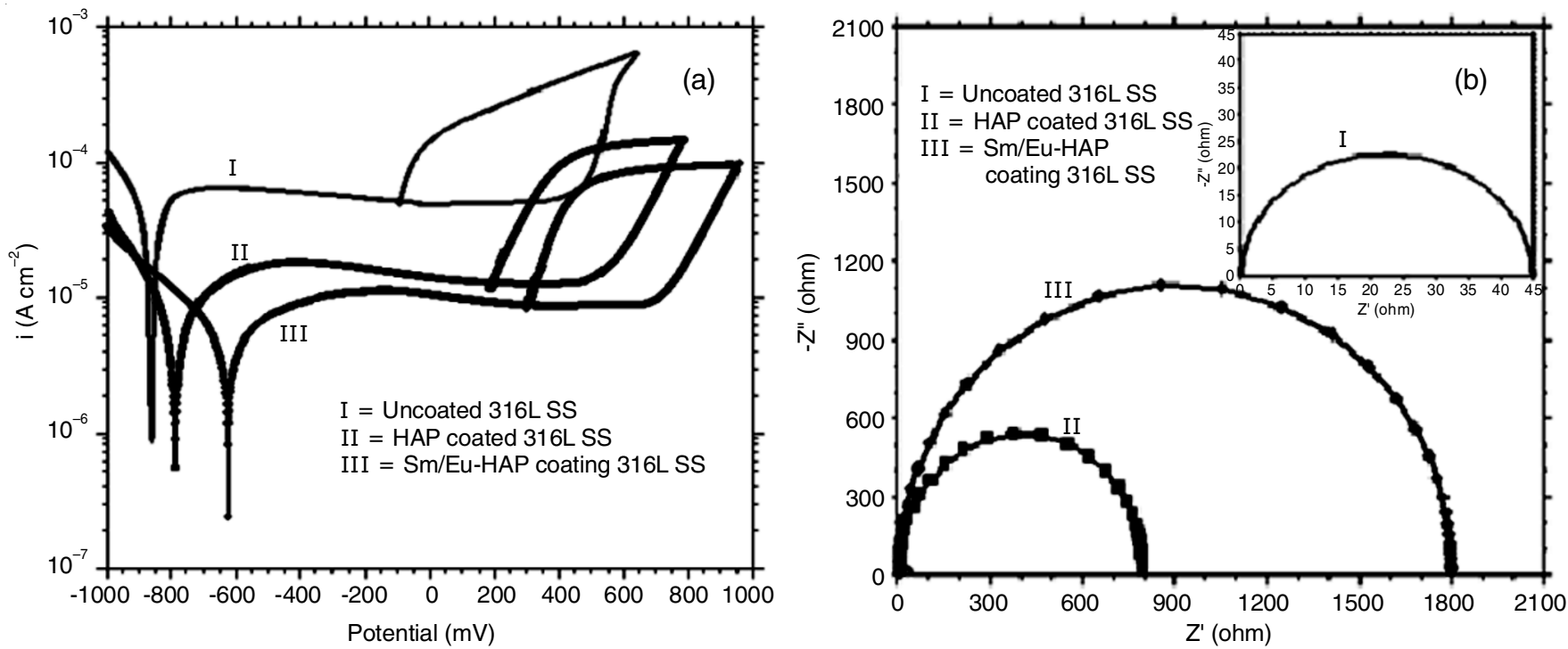

Fig. 4. (a) Potentiodynamic polarization curves (b) Impedance spectra of uncoated, HAP coated, Sm/Eu-HAP coated on 316L stainless steel 


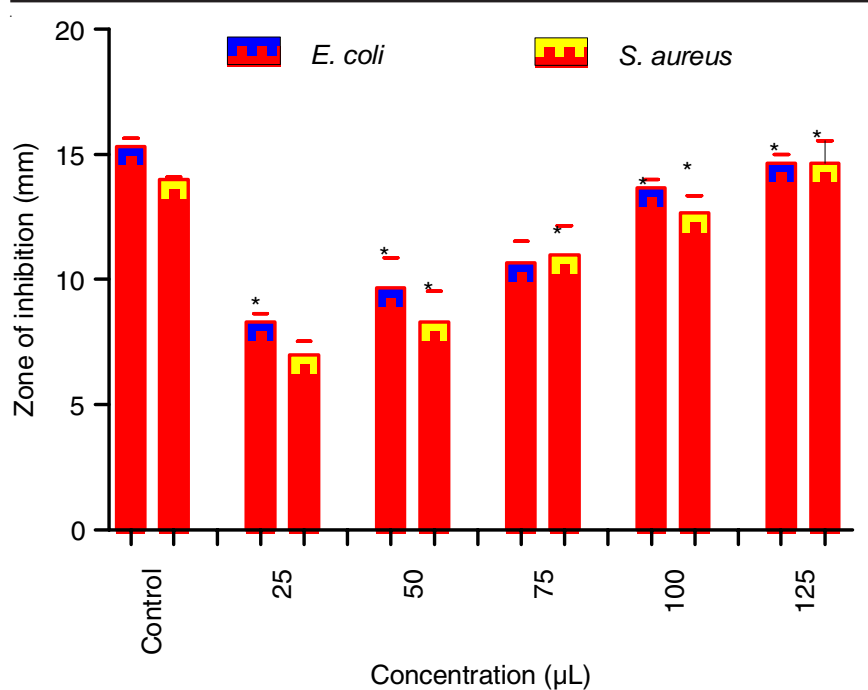

Fig. 5. Comparison of antibacterial activities of Sm/Eu-HAP coating at different concentrations against pathogenic bacteria $E$. coli and $S$. aureus $(*)$ denotes a significant difference compare to the control $(\mathrm{P} \leq 0.05)$

live cells and red cells are dead cells and used the dye components such as AM is green and ethidium homodimer used are red. The live/dead cultured on Sm/Eu-HAP coated samples

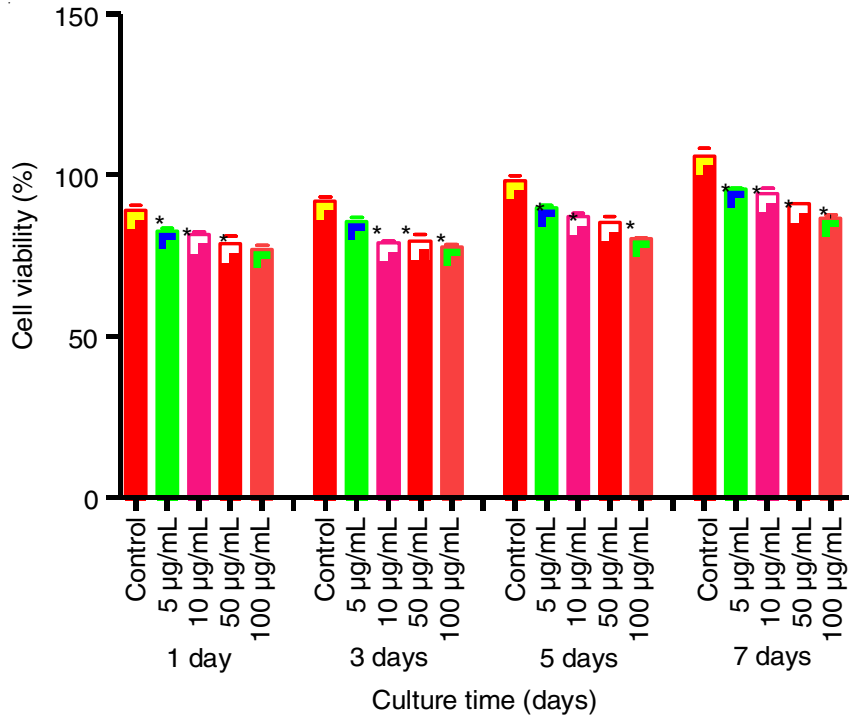

Fig. 6. in vitro cell viability results of Sm/Eu-HAP coating on MC3T3-E1 cells for $1,3,5$ and 7 days $(*)$ denotes a significant difference compare to the control $(\mathrm{P} \leq 0.05)$

seemingly increased over the period. Since, increasing the live cells at day 3 was significantly higher than at day 1 . However, increasing the culture time to 5 days and 7 days the lives cells
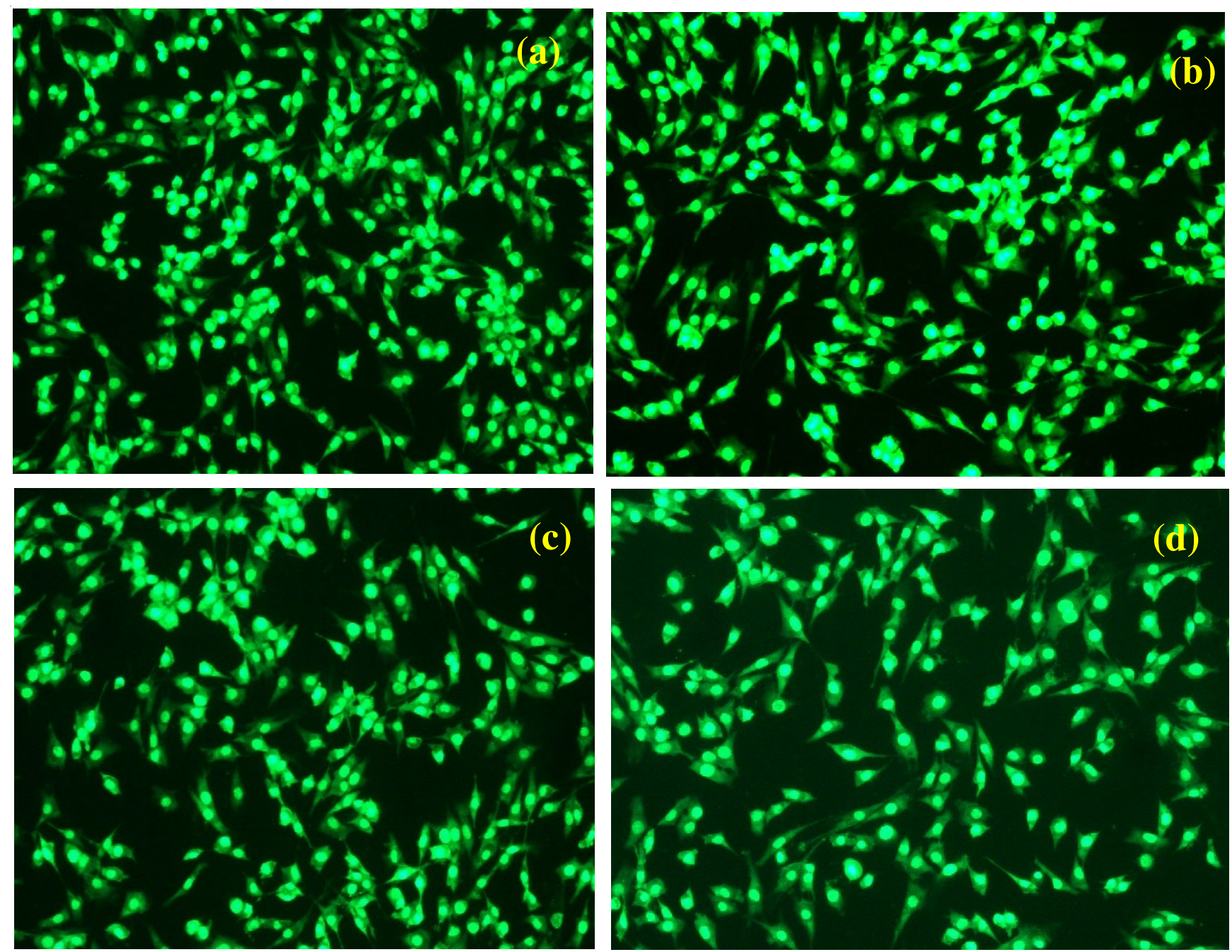

Fig. 7. Live/dead fluorescence microscopic images of (a) Sm/Eu-HAP coating on 1 day (b) Sm/Eu-HAP coating on 3 days (c) Sm/Eu-HAP coating on 5 days (d) Sm/Eu-HAP coating on 7 days 
spreading morphology are also increases. Although comparing the different days (1, 3, 5 and 7) Sm/Eu-HAP coating superb cell growth and elongated morphology on 7 day, compared with other $(1,3,5)$ days. Thus the live/dead fluorescence images clearly indicated that $\mathrm{Sm} / \mathrm{Eu}-\mathrm{HAP}$ coated samples extensively increases the growth and viability of cells which is favourable for biomedical applications.

\section{Conclusion}

In present study a Sm/Eu-HAP coating on 316L stainless steel. The results are summarized as follows:

- The presence of functional groups in Sm/Eu-HAP coating was confirmed by the FT-IR and crystalline nature on $\mathrm{Sm} /$ Eu-HAP coating confirmed by XRD analysis.

- The surface morphology of Sm/Eu-HAP $\left(9 \mathrm{~mA} / \mathrm{cm}^{2}\right)$ coated on $316 \mathrm{~L}$ stainless steel exhibited the formation of completely covered the rod like structure. The EDAX spectrum establishes the presence of $\mathrm{Sm}, \mathrm{Eu}, \mathrm{Ca}, \mathrm{P}$ and $\mathrm{O}$ on $\mathrm{Sm} / \mathrm{Eu}$ HAP coated surface.

- The electrochemical studies revealed Sm/Eu-HAP coating on 316L stainless steel sample indicated a maximum shift in the noble direction when compared to that of HAP coated and the uncoated 316L stainless steel specimens.

- $\mathrm{Sm} / \mathrm{Eu}-\mathrm{HAP}$ coating showed strong antibacterial activity against both Gram-positive and Gram-negative bacteria like $S$. aureus and E. coli respectively.

- The cell viability and live/dead fluorescence results showed non-toxic nature and superb elongated morphology of Sm/Eu-HAP coating on MC3T3-E1 cultures. In summary $\mathrm{Sm} / \mathrm{Eu}-\mathrm{HAP}$ coating on 316L stainless steel enhances corrosion resistance and biological properties. Hence, the bio implant superb osseointegration capability use for suitable in biomedical applications.

\section{CONFLICT OF INTEREST}

The authors declare that there is no conflict of interests regarding the publication of this article.

\section{REFERENCES}

1. S. Kannan, A. Balamurugan and S. Rajeswari, Mater. Lett., 57, 2382 (2003); https://doi.org/10.1016/S0167-577X(02)01239-9.
2. G. Manivasagam, D. Dhinasekaran and A. Rajamanickam, Recent Patents Corros. Sci., 2, 40 (2010); https://doi.org/10.2174/1877610801002010040.

3. F. Pishbin, V. Mourino, J.B. Gilchrist, D.W. McComb, S. Kreppel, V. Salih, M.P. Ryan and A.R. Boccaccini, Acta Biomater., 9, 7469 (2013); https://doi.org/10.1016/j.actbio.2013.03.006.

4. E. Leitao, R.A. Silva and M.A. Barbosa, Corros. Sci., 39, 333 (1997); https://doi.org/10.1016/S0010-938X(97)83349-5.

5. Y. Tang, S. Katsuma, S. Fujimoto and S. Hiromoto, Acta Biomater, 2, 709 (2006); https://doi.org/10.1016/j.actbio.2006.06.003.

6. T. Tuken, Surf. Coat. Technol., 200, 4713 (2006); https://doi.org/10.1016/j.surfcoat.2005.04.011.

7. M. Sivakumar and S. Rajeswari, J. Mater. Sci. Lett., 11, 1039 (1992); https://doi.org/10.1007/BF00729754.

8. T.M. Sridhar, T.K. Arumugam, S. Rajeswari and M. Subbaiyan, J. Mater. Sci. Lett., 16, 1964 (1997); https://doi.org/10.1023/A:1018511406374.

9. S.M.A. Shibli and A.C. Jayalekshmi, Appl. Surf. Sci., 254, 4103 (2008); https://doi.org/10.1016/j.apsusc.2007.12.051.

10. A. Kocijan, C. Donik and M. Jenko, Corros. Sci., 49, 2083 (2007); https://doi.org/10.1016/j.corsci.2006.11.001.

11. M. Chozhanathmisra, D. Govindaraj, P. Karthikeyan and R. Rajavel, Asian J. Chem., 30, 2264 (2018); https://doi.org/10.14233/ajchem.2018.21423.

12. M.F. Hsieh, L.H. Perng and T.S. Chin, Mater. Chem. Phys., 74, 245 (2002); https://doi.org/10.1016/S0254-0584(01)00474-6.

13. D. Lakstein, W. Kopelovitch, Z. Barkay, M. Bahaa, D. Hendel and N. Eliaz, Acta Biomater., 5, 2258 (2009); https://doi.org/10.1016/j.actbio.2009.01.033.

14. H. Hu, W. Zhang, Y. Qiao, X. Jiang, X. Liu and C. Ding, Acta Biomater, 8, 904 (2012); https://doi.org/10.1016/j.actbio.2011.09.031.

15. K. Huo, X. Zhang, H. Wang, L. Zhao, X. Liu and P.K. Chu, Biomaterials, 34, 3467 (2013); https://doi.org/10.1016/j.biomaterials.2013.01.071

16. D.S. Morais, J. Coelho, M.P. Ferraz, P.S. Gomes, M.H. Fernandes, N.S. Hussain, J.D. Santos and M.A. Lopes, J. Mater. Chem. B, 2, 5872 (2014); https://doi.org/10.1039/C4TB00484A.

17. C.S. Ciobanu, C.L. Popa and D.J. Predoi, J. Nanomater, 2014, Article ID 780686 (2014); https://doi.org/10.1155/2014/780686

18. G. Clunie, D. Lui, I. Cullum, J.C.W. Edwards and P.J. Ell, J. Nucl. Med., 36, 51 (1995).

19. F. Chen, P. Huang, Y. Zhu, J. Wu, C. Zhang and D. Cui, Biomaterials, 32, 9031 (2011); https://doi.org/10.1016/j.biomaterials.2011.08.032. 